\title{
Forest Biomass and Paper Industry, a Pathway to Green Biofuels
}

\author{
By Miyuru Kannangara* \\ Mariya Marinova \\ Michel Perrier ${ }^{+}$ \\ Jean Paris ${ }^{\dagger}$
}

The components of wood, celluloses, hemicelluloses and lignin, can be separated and converted into new non paper products. This paper treats the specific case of lignin and hemicellulose extraction from a Kraft pulping process. Two processes have been investigated for the extraction of lignin from black liquor. One is an enhanced version of precipitation of lignin under low $\mathrm{pH}$ conditions achieved by carbonation of Kraft black liquor. The second process focuses on the acidification of the black liquor by electrodialysis with a bipolar membrane. This process produces clean lignin and valuable caustic soda. The extraction of hemicelluloses from wood chips and their partitioning into a mixture of C5 and C6 sugars can be accomplished by a two-step hydrolysis. The sugars can then be converted into a large number of derivatives. The case of fermentation into butanol is presented. The energy intensification of the site eliminates the requirement for fossil fuel thus enhancing the feasibility of the green integrated forest biorefinery.

Keywords: Bioproducts, conversion of hemicelluloses, extraction of lignin, forest biomass, forest biorefinery, green integrated forest biorefinery

\section{Context of the Work}

The Pulp and Paper industry (P\&P) in industrially mature countries has been facing lasting precarious business conditions. There are two main reasons for this situation.

- A declining demand for commodity papers (newsprint, printing and writing papers) caused by the spectacular development of electronic communication as illustrated Figure 1;

- The competition from emerging economies in tropical regions benefiting from low labor costs and fast growing forest feedstock where large and modern facilities are being built.

\footnotetext{
* Polytechnique Montreal, Canada.

* Researcher, Polytechnique Montreal, Canada.

${ }^{+}$Professor, Polytechnique Montreal, Canada.

${ }^{\dagger}$ Professor, Polytechnique Montreal, Canada.
} 
It must also be recognized that energy efficiency upgrading, in the past, has not received the attention that it should have. Increased energy costs have become a strong motivating factor of change in that regard.

The P\&P industry has aggressively investigated and developed new and innovative products derived from the forest biomass to penetrate non paper oriented markets and generate additional profits. Some of those products are novel utilisations of a wood component to manufacture original types of paper products or new forms of the cellulose fiber itself. Examples of new types of paper products are:

- Bio sensitive paper for food packaging which can detect the rupture of the contamination barrier,

- Security paper with embedded codes at the manufacturing stage and,

- New packaging materials for the e-commerce.

Figure 1. Evolution of the Demand in Paper Products

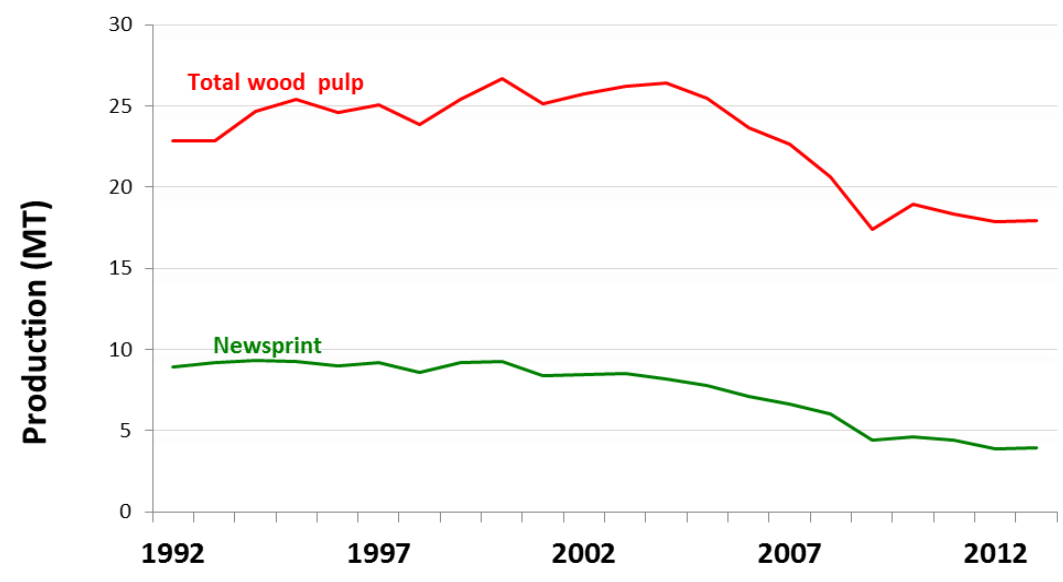

Bio-sensitive and security papers are at the pre-manufacturing pilot plant stage. E-commerce packaging materials are commercially available in response to a fast growing demand. Other traditional paper products such as household and personal care paper products or industrial application papers (support to isolations, thermal transfer papers, and paint masking tape) maintain their market positions. Nevertheless, these positive factors cannot compensate for the loss of large scale commodity papers formerly used as communication support. The decrease in the demand of paper products in the last four years can be seen in Figure 1.

Novel utilisations of the cellulose fibers themselves in different forms is a fast developing field, which include nano-crystalline cellulose, nano-fibrillated cellulose and cellulose filaments. Nanocellulose, crystalline or fibrillated, imparts specific properties to composite materials into which they are incorporated. There are many potential applications for nanocellulose in the automotive and aeronautic industries. The price is high but the volume relatively small. Cellulose filaments can be used as a paper strengthening agent. 
Another way to contribute to the profitability of the P\&P sector consists of treating the woody biomass as an organic feedstock which can be partitioned into its main components (cellulose, hemicelluloses and lignin) that can then be transformed into biofuels and bioproducts by various chemical pathways. This wood partitioning and transformation process is called the forest biorefinery by analogy with the petroleum refinery. When the two steps of this process, partitioning and conversion, are done on the site of an existing $\mathrm{P} \& \mathrm{P}$ mill it is called the integrated forest biorefinery (IFBR). The concept of IFBR, its advantages and challenges, its practical implementation to manufacture biofuels are examined in this paper.

During the last two decades, the P\&P industry has investigated the possibility to modify its current equipment and infrastructure so that they may be used to separate the components of wood and convert them into novel non paper bioproducts. This work has led to the concept of integrated forest biorefinery. The three main components of wood that can be processed in a biorefinery are cellulose, hemicelluloses and lignin.

\section{The Concept of Integrated Forest Biorefinery}

The integrated forest biorefinery illustrated in Figure 2 consists of two main process units, a receptor $\mathrm{P} \& \mathrm{P}$ mill and a biorefinery plant. The receptor mill is an existing and operating mill. In the case studies presented below there is a Kraft mill but the work is being extended to other pulping processes, i.e., thermo mechanical pulping and sulfite pulping. The feedstock to the biorefinery plant is a diverted fraction of a process stream of the $\mathrm{P} \& \mathrm{P}$ mill rich in a wood component that can be converted into a biofuel or another bioproduct. For strategic reasons streams containing lignin or hemicelluloses were selected first because the earlier work on the development of new products that could be made from wood biomass was focused on cellulose fibers as mentioned above. The biorefinery plant could also treat wood residues from saw mills or pulp and paper mills. This possibility will not be treated in this paper.

A very important feature of the integrated forest biorefinery is that the two main processes units be highly integrated from the stand point of thermal energy (steam), water and, wherever possible from the stand point of chemicals. Process integration will minimize the need for imported fuels and materials. Actually, as will be seen later, the global steam and water consumption of the integrated biorefinery may be inferior to that of the current P\&P mill alone provided energy intensification and integration measures are implemented.

The main advantages of the integrated forest biorefinery versus a standalone facility are significant: 
Figure 2. The Integrated Forest Biorefinery Concept

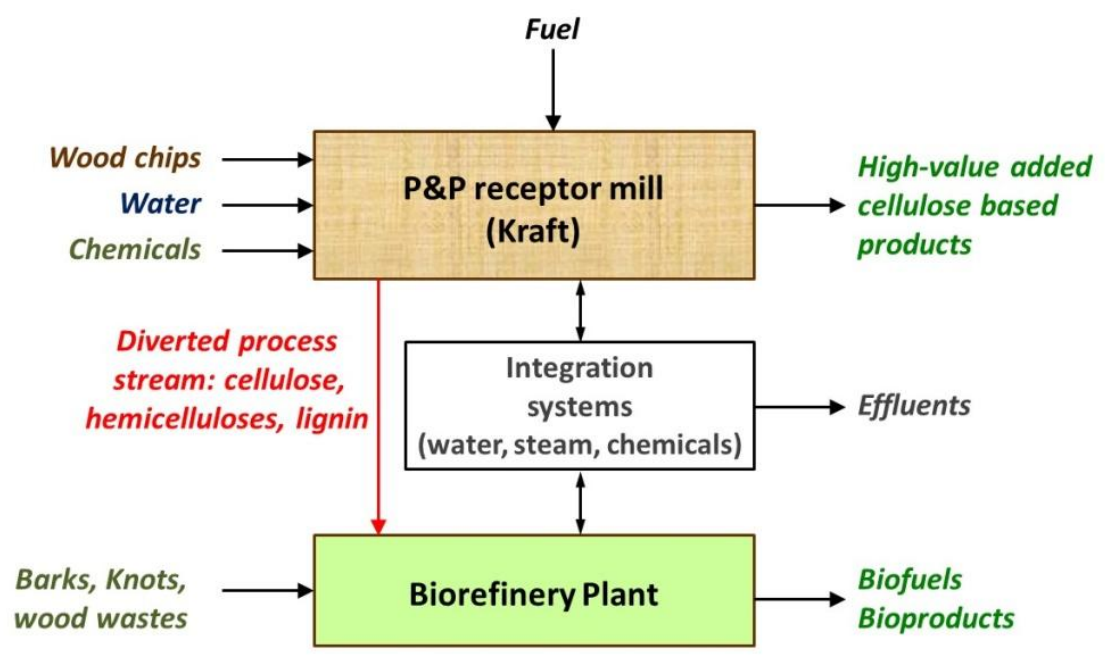

- Existing infrastructures can be shared by receptor mill and biorefinery plant (power plant and utility systems, wood yard, store room and shipment hall, docks, laboratories and effluent treatment);

- The feedstock to the biorefinery is delivered on site;

- Networks of suppliers and contractors are already fully developed and operational;

- Transport networks by railway, road or waterway are implemented and operational and,

- Very important since P\&P mills are usually in rural areas and sometimes distant from large centers (as is the case in Canada), a highly trained and competent manpower is already available on site.

Examples of lignin and hemicelluloses biorefineries developed to preengineering stage by the authors, their associates and students are presented below.

\section{The Lignin Biorefinery}

Lignin is a complex three dimensional polymer consisting primarily of phenylpropane units. It has a relatively high calorific value and can be combusted to generate heat and power. It can also be converted into liquid transportation fuels through gasification, pyrolysis and Fischer Tropsch pathways. The first step of the Kraft pulping process is the delignification of wood chips to liberate cellulose fibers forming the pulp. This is accomplished by chemical action under strong alkaline and high temperature conditions. The solubilised lignin is entrained by the spent delignification liquor (black liquor, BL) which is concentrated and burnt to produce heat and power. In the integrated forest biorefinery, the lignin can be precipitated by the acidification of the black liquor, 
purified and dried and, used as a precursor to the vast phenolic platform of chemical pathways. Two parallel case studies using drastically different acidification techniques have been undertaken; one consists of sparging $\mathrm{CO}_{2}$ in $\mathrm{BL}$ and the other uses electrodialysis with bipolar membranes to separate a lignin enriched stream from a caustic soda enriched stream. It has been found that the behavior of the generated particulate lignin controls the efficiency of both the techniques and remedial actions that are being investigated.

\section{Acidification by $\mathrm{CO}_{2}$ Sparging}

The basic process flow diagram for the acidification of black liquor by carbonation is well established (Figure 3); there are two variations, Lignoboost developed in Sweden and Lignoforce developed in Canada (Tomani, 2010; Kouisni et al., 2012). However there are still areas for improvement or optimization. Two recent developments are summarized below, one concerns the impact of the integration of the biorefinery process on the chemical balance of the Kraft receptor mill, and the other concerns the flocculation and filterability of the precipitated lignin. The lignin extraction rate was fixed at $15 \%$ and the pulp production rate was increased proportionately to maintain the recovery boiler at full capacity. In most Kraft mills, the recovery boiler is the capacity limiting equipment. The energy deficit caused by the withdrawal of lignin was compensated by implementing intensive energy intensification and integration measures (Kannangara et al., 2012). The critical sodium to sulfur balance of the mill was disrupted and remedial actions were taken primarily by rebalancing the wash water networks. A laboratory scale experimental program was undertaken to determine the process parameters controlling the flocculation steps. The hydrodynamic conditions during those unit operations were varied and the precipitated lignin particles were characterized in terms of size and shape. It was observed that the size and density of the lignin particles could be controlled by the hydrodynamic parameters (agitation intensity) of the aging steps. Larger and more compact particles produce superior filtration and washing results (Kannangara, 2015).

Figure 3. Process Flow Diagram for the Precipitation of Lignin by $\mathrm{CO}_{2}$ Injection

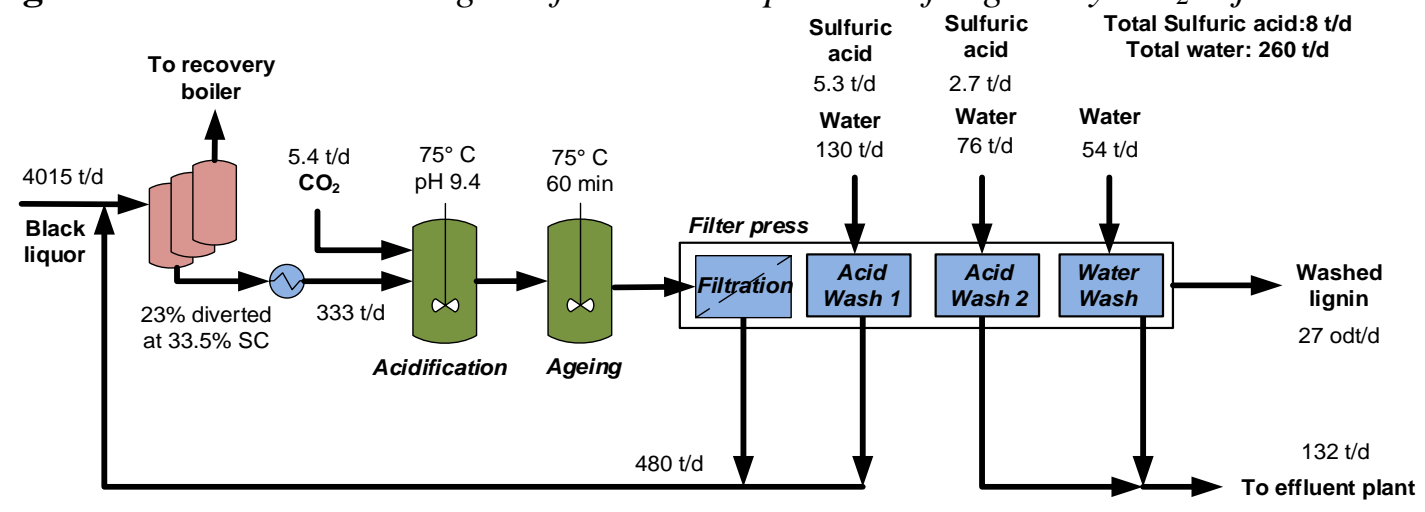




\section{Lignin Separation by Electrodialysis}

Black liquor consists of conductive electrolytes such as $\mathrm{Na}_{2} \mathrm{CO}_{3}, \mathrm{Na}_{2} \mathrm{~S}$, $\mathrm{Na}_{2} \mathrm{SO}_{4}$, organic sodium salts as well as non-electrolytes. Therefore, a bipolar membrane electrodialysis acidification technique could be an effective approach for lignin extraction from the BL. The bipolar membrane electrodialysis of the BL requires a significantly reduced chemical consumption in comparison to acid precipitation methods and simultaneously recaptures caustic soda. A two compartments-type cell of the bipolar membrane electrodialysis, containing a stack of alternating series of BPMs (bipolar membranes) and CEMs (cation exchange membranes) was used to evaluate the efficiency of the technique (Figure 4). The electrical field was applied as the driving force to acidify the BL and lower its $\mathrm{pH}$ as much as possible without lignin precipitation inside the electrodialysis cell. The bipolar membrane electrodialysis acidification process was followed by a simple filtration step to separate the lignin from the acidified BL. The residual liquor or filtrate could be sent back to a recovery boiler while the extracted lignin can be used as a value added product.

Figure 4. BMCD Configuration (BPM: Bipolar Membrane, CEM: Cation Exchange Membrane)

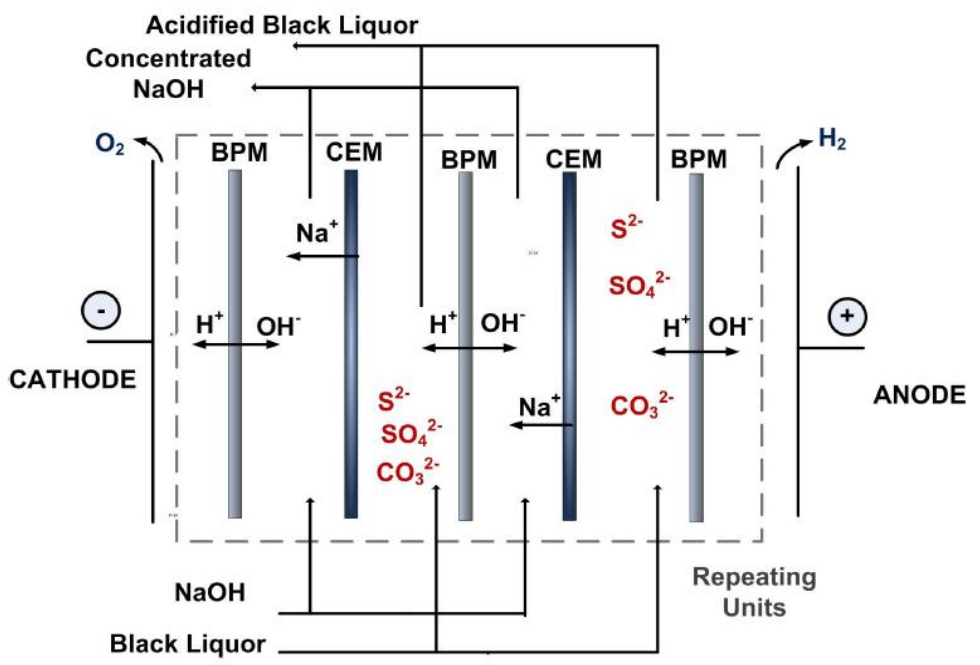

The focus was on the effect of process conditions, of fouling patterns and of the impact of the pulsed electric field on the performance of the process in order to make bipolar membrane electrodialysis acidification economically feasible. An example of operation of the bipolar membrane electrodialysis cell is shown in Figure 5. A quantitative framework based on the design of experiments and statistical analysis was developed to evaluate the contribution of operating conditions, membrane fouling and pulse electric field application on the performance of bipolar membrane electrodialysis acidification of the balck liquor. The experiments performed in the course of this study provided valuable knowledge for a practical bipolar membrane electrodialysis design and to evaluate the potential and operating conditions of BMED as a promising method for BL acidification and lignin extraction (Haddad et al., 2015). 
Figure 5. Schematic of a Black Liquor Acidification Process by Electrodyalisis withBbipolar Membrane

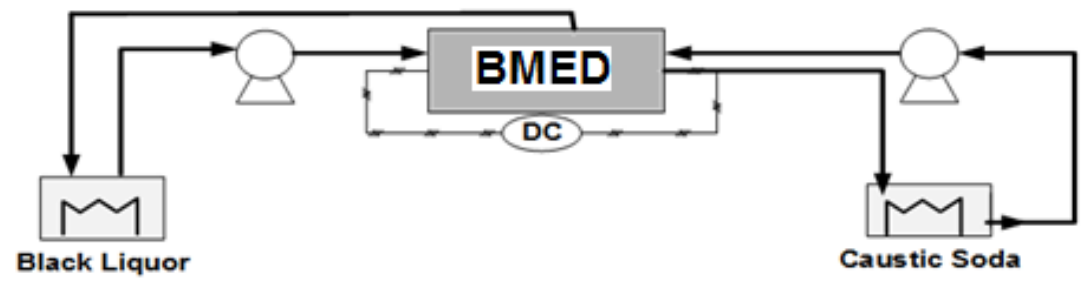

\section{The Hemicelluloses Biorefinery}

Hemicelluloses are polymers of pentose and hexose sugars that can be hydrolyzed into sugar monomers following a conditioning pre-treatment. The monomers can then be fermented into alcohols, which are used as bio-additives to gasoline. Extraction of hemicelluloses from wood chips by partial hydrolysis is performed in some Kraft pulping processes which produce a wood pulp with high fiber content, called dissolving pulp. This pulp is used as a feedstock for downstream chemical processing of cellulose to make, for example, rayon, a textile fiber. Part of the prehydrolysate stream can be diverted to a biorefinery (Figure 6). However it would be very costly to install this extra processing step in Kraft mills which are already operational. Another way to extract hemicelluloses from the wood biomass could be by reactive extrusion. This technique is receiving attention and has been demonstrated at the pilot plant level.

Figure 6. The Integrated Hemicelluloses Biorefinery (Case of Dissolving Pulp)

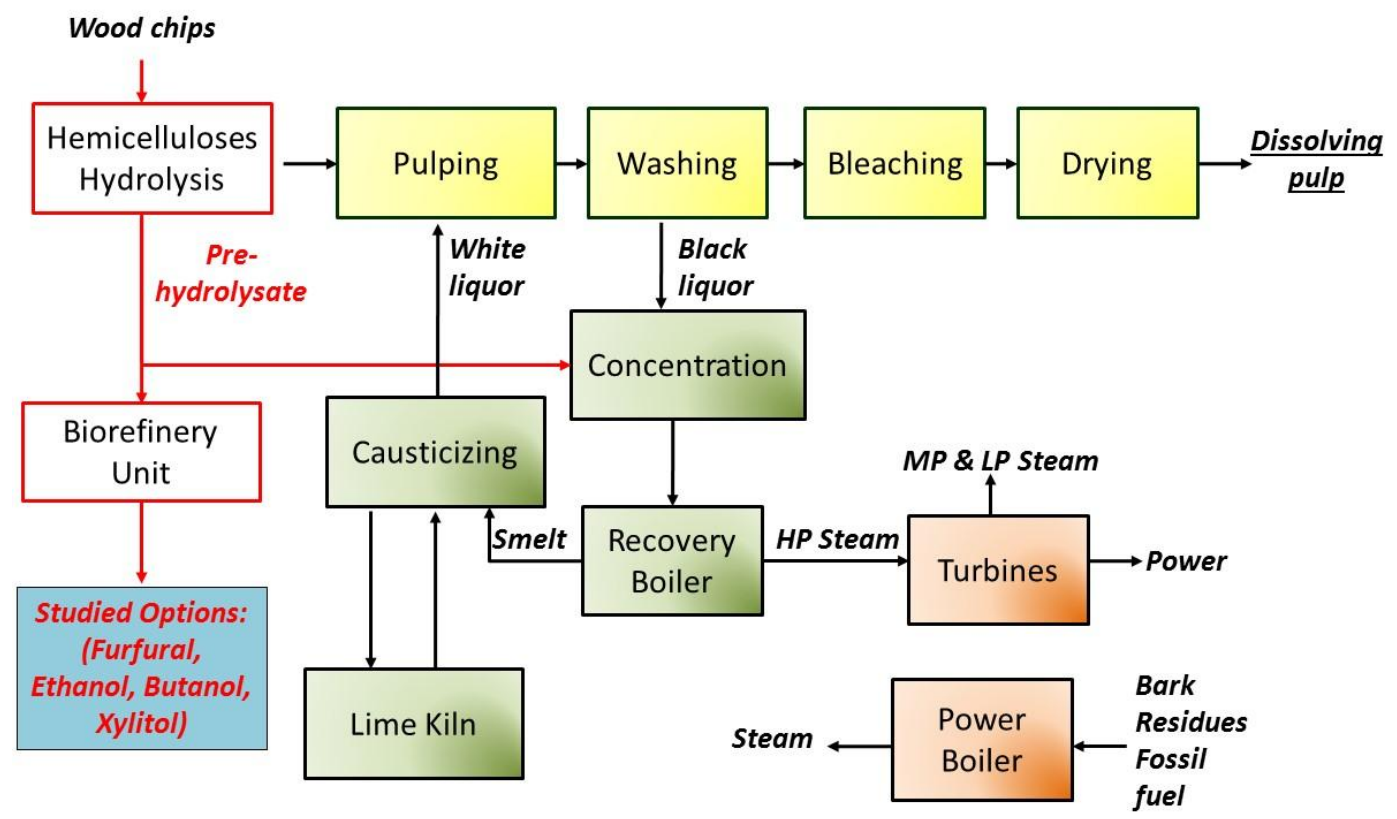


Feasible process flow diagrams have been developed for the conversion of hemicelluloses from the prehydrolysate stage to various products. A block diagram of typical but general conversion process is given in Figure 7. Specific conversion processes have been developed to the pre-engineering stage and simulation models have been implemented on the software ASPEN Plus to guide experimental work and support process analysis and optimisation studies. The specific case of the production of butanol from a hemicelluloses stream is illustrated in Figure 8. This process incorporates original technologies which are the object of patent applications concerning the hydrolysate detoxification step and, the enhancement of the fermentation step.

\section{Hydrolysate Detoxification}

The wood chips prehydrolysate contains a large fraction of the hemicelluloses of the wood $(40 \%)$ as oligomers and monomer sugars but, it also contains components resulting from the degradation of wood that could hinder the fermentation of sugars to achieve its full potential extent. These inhibitors are organic acids, furan and phenolic components. Two techniques are being used to obtain, by their combination, a high degree of detoxification. One technique is a two step membrane separation, a microfiltration to remove the lignin and other suspended solids and a nanofiltration to remove low molecular weight components such as organic acids and furans. The membrane separation steps also increase the concentration of sugar oligomers and monomers by water removal. The second technique is the entrainment of high molecular weight phenolic components by flocculation with ferric sulfate. Furthermore, it was observed that the best overall results were obtained when the detoxifications and finishing hydrolysis steps were performed in a specific order, i.e. membrane filtration, finishing hydrolysis and, flocculation as indicated on Figure 7.

Figure 7. General Conversion Process of Hemicelluloses to Value Added Products

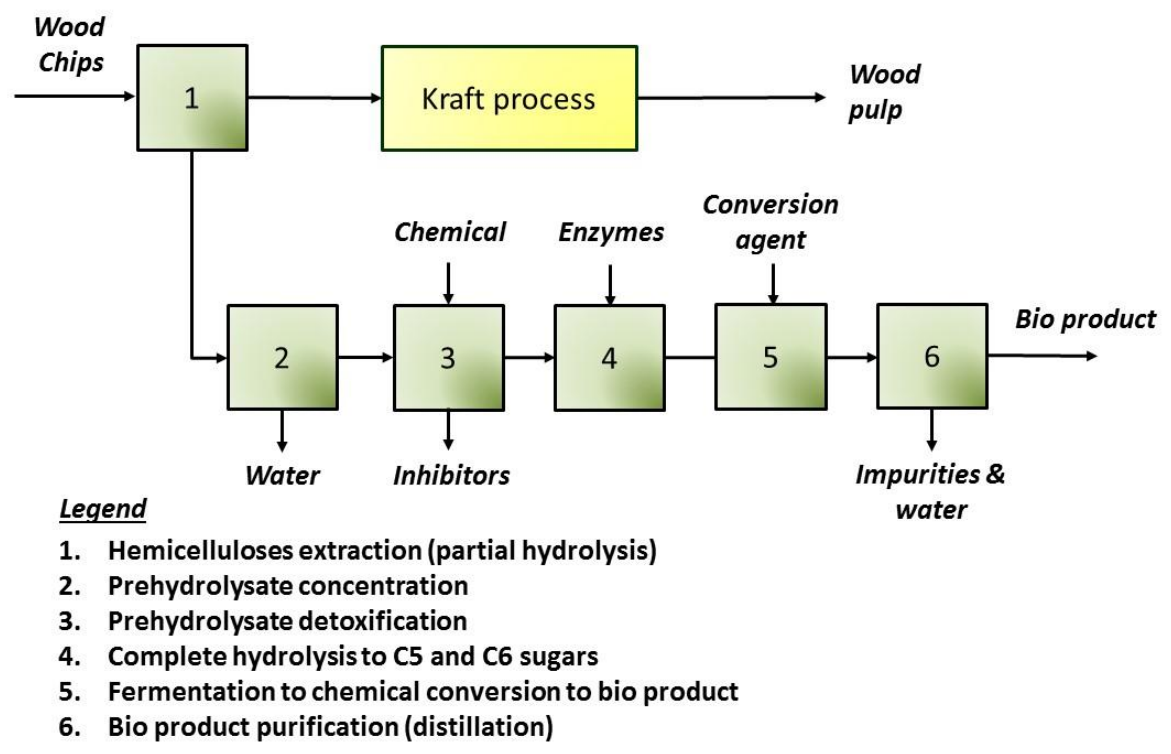


Figure 8. Process Diagram for the Conversion of Hemicelluloses into Butanol

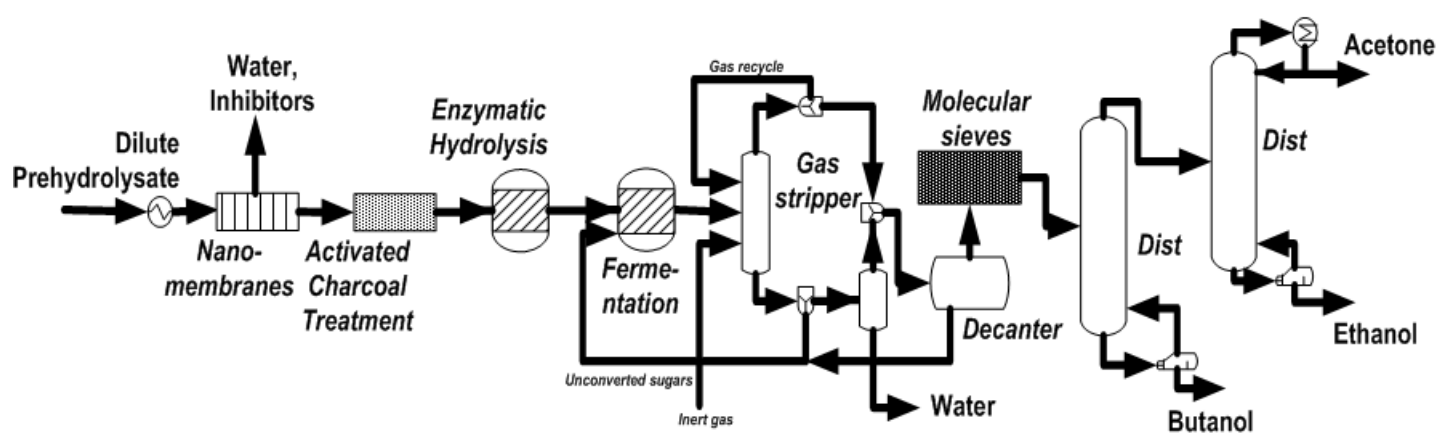

\section{Fermentation Enhancement}

The Acetone-Butanol-Ethanol (ABE) fermentation is a well mastered technique to produce butanol from a mixture of C5 and C6 sugars using clostridium acetobutilicum as the fermentation agent. However the yield in butanol is low $(\mathrm{xxG} / \mathrm{L})$ unless the fermentation medium is enriched by a nitrogen supplement. The commonly used nitrogen supplement is a costly yeast extract. I was shown at the laboratory level that the substitution of yeast extract by alfalfa juice could produce the same butanol yeast at a much lower cost. Alfalfa also known as lucerne is a commonly grown fodder under a broad range of climates. The juice was extracted from freshly harvested alfalfa by a simple grinding and pressing procedure and kept at $-20^{\circ} \mathrm{C}$ until used. Benchtop experiments were conducted in $250 \mathrm{ml}$ Schott bottles using scylose as a source of carbon. Parallel experiments were conducted using alfalfa juice or yeast extract at the same level of nitrogen supply $(0.9$ and $1.5 \mathrm{G} / \mathrm{L}$ of nitrogen). The corresponding experiments with the two sources of nitrogen produced the same butanol yield $(x x G / L)$ that is an increase of $38 \%$ in the enriched fermentation media. The results will be validated at a larger laboratory scale $(10$ to $100 \mathrm{~L})$. Patents have been submitted for the two novel process steps proposed for the detoxification of the hydrolysate and for fermentation with alfalfa medium.

\section{The Green Integrated Forest Biorefinery}

The green integrated forest biorefinery is an industrial complex comprising four revenue generating centers (Figure 9) and which does not consume any energy of fossil origin. The four units of a GIFBR are;

- A pulp making plant. In the initial stage of this project, this plant was a Kraft mill; the work has since then been extended to thermomechanical pulping.

- A biorefinery unit treating lignin or hemicelluloses supplied by the pulp plant. The pulp plant and biorefinery unit are highly integrated from the stand part of energy (steam), water and chemicals. 
- A wood biomass gasifier. The primary function of this equipment is to supply biogas to the lime kiln of the pulp mill. In general the lime kiln is fired with natural gas. Replacing this fossil fuel by a biogas is a condition to achieve the status of the green industrial site. The economics of the gasifier plant can be significantly improved if it is designed to produce steam and syngas that can be converted to a bioproduct. Production of methanol is feasible and could be attractive depending on the market conditions.

Figure 9. The Green Integrated Forest Biorefinery

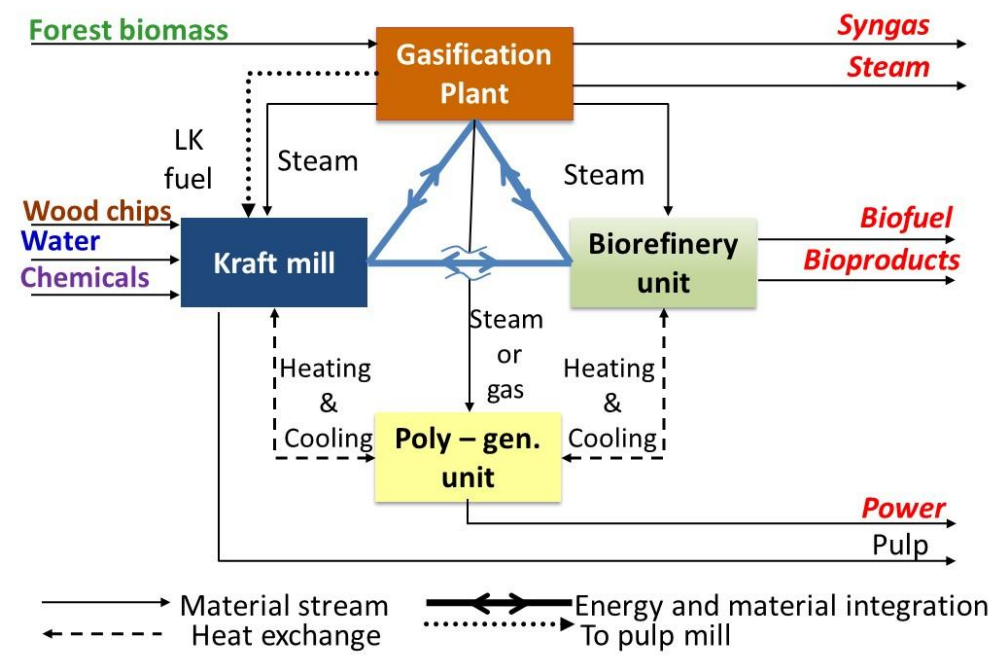

The viability of the GIFBR depends largely on of the energy efficiency of the pulp making plant especially when the receptor mill is a Kraft pulping mill, an energy intensive process. In order to help Kraft mills improve their energy performance by the rational and progressive implementation of energy enhancement projects an original and innovative methodology has been developed (Keshthkar, 2013; Keshthkar et al., in press). It is based on the following principles:

- A stepwise procedure

- The combined analysis of steam and water systems

- The use of heuristic rules derived from experience

- A project oriented structure

Figure 10 illustrates the interactions between energy and water systems (Mateos-Espejel et al., 2011). The methodology has been validated by its application to three operating Canadian Kraft mills. The results obtained were significantly superior to those obtained by the current engineering practice. The main results are displayed in Figure 11. 
Figure 10. Schematic of Interactions between Energy and Water Systems in a Pulping Mill

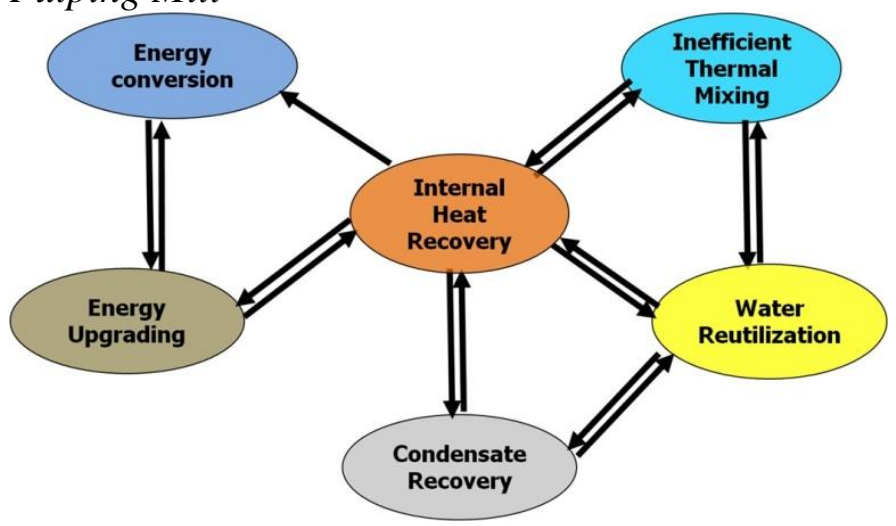

Figure 11. Results Obtained by the Application of the Energy Efficiency Enhancement Methodology to Three Kraft Mills

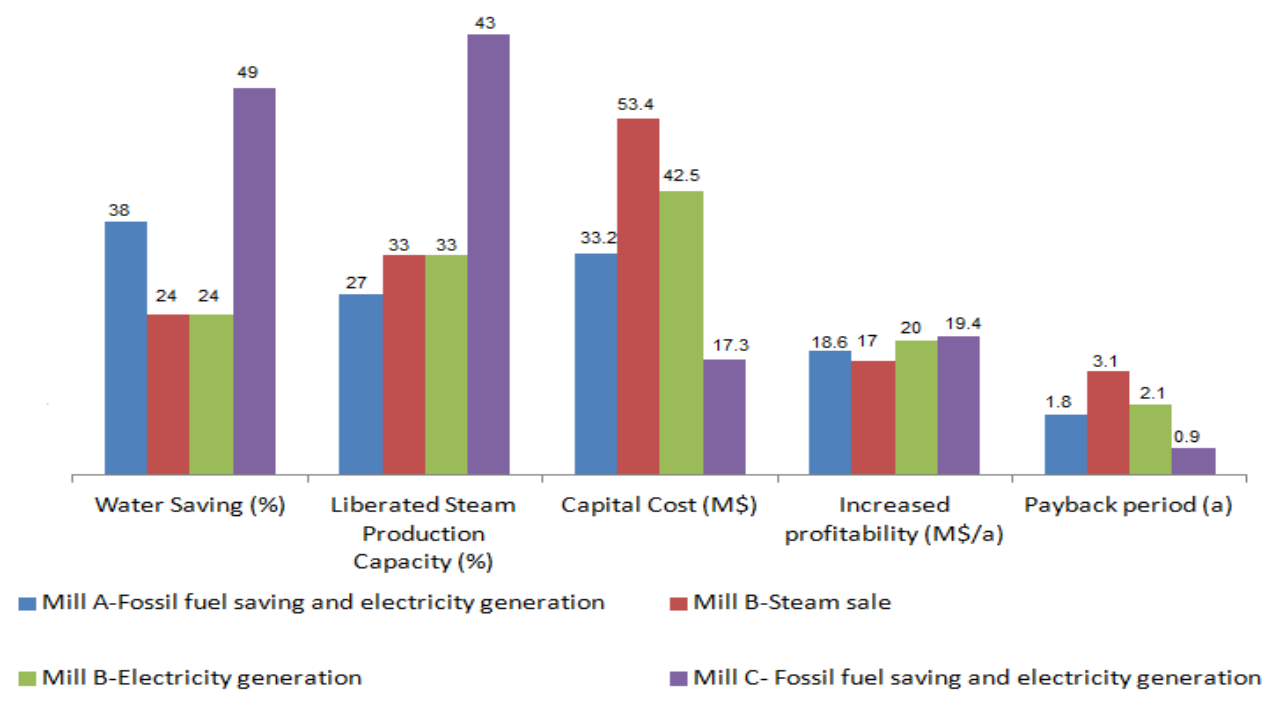

\section{The Green Integrated Biorefinery and Climate Change}

The pulp and paper manufacturing industry is a major industry in industrially mature regions in North America and Europe. It is also a fast developing industry in tropical regions with abundant forest resources such as northern Brazil and Indonesia, as well as in the new power house of central and eastern Asia lead by China and India. If measures are not taken to significantly reduce greenhouse gas emissions from the old and new plants and from those that will be built, the industry will be a significant contributor to the greenhouse effect.

It is acknowledged by the scientific community that the stabilization of the climate of the earth will require very significant progress in three ways that energy is produced and used (Meunier, 2008).

- Rational use of energy 
- Development of renewable sources of energy

- Capture of $\mathrm{CO}_{2}$ on site, i.e. at the point at which it is produced.

The concept of green integrated forest biorefinery clearly addresses the first two points in a very significant way by increasing significantly the energy efficiency of the total industrial site and totally eliminating the use of fossil fuels. Furthermore, it can be argued that GIFBR is a part of a global forest ecosystem which has a zero net $\mathrm{CO}_{2}$ footprint.

\section{Conclusions}

Several technical challenges must be addressed to stimulate and accelerate the implementation of the IFBR.

- Partitioning of cellulose into glucose monomer is a difficult step which requires elaborate and expensive Thermomechanical pretreatments. This challenge can be solved by analysing and improving the bio-mechanism of the conversion process. The work on this subject is in progress.

- The extraction of lignin from black liquor is limited $(20 \%)$ by the combustibility of the black liquor in the recovery boiler. Substituting wood waste (knots, bark, sawdust from sawmills) to lignin as fuel in the recovery boiler may be a way to increase the amount of lignin that can be extracted from black liquor.

- Hydrolysis of hemicelluloses from wood chips is also limited to $35 \%$ for similar reasons. Furthermore, chips hydrolysis is only practiced in some mills producing dissolving pulp. Installing this process step in operating mills would be a very costly undertaking. New extraction methodologies are being considered as an alternative solution.

- The chemicals produced by the integrated forest biorefinery will be precursor or commodity products that will be inserted into the downstream processing chain that is in the manufacturing processes of the chemical or petrochemical industries. The requirements and demands of the downstream chemical manufacturers will have to be met by the bioproducts being delivered at the gate of the biorefinery complex.

It has been shown that the concept of integrated forest biorefinery is feasible. It may eventually lead to complete conversion of paper mills into biomass processors. Feasible processes have been developed for hemicelluloses and lignin. However, the rate of withdrawal must be increased. Biorefinery clusters could be an option to increase the production capacity and profitability of the IFBR.

Currently, the work is being extended to the cellulose biorefinery. Insertion into the downstream chemical production chain is a delicate issue. Energy efficiency is an imperative requirement of economic feasibility of the forest biorefinery. A new, innovative methodology has been developed to enhance the efficiency of biorefinery sites. It has been validated by application to three Canadian Kraft 
mills. The results have shown that very significant progress can be achieved in typical Canadian pulping mills.

\section{References}

Haddad M., Bazinet. L, Savadogo O., Paris, J. (2015) "Impact of Pulsed Electric filed on Bipolar membrane Electrodialysis Acidification of Kraft Black Liquor", Euromembrane Conference, Aachen, Germany.

Kannangara, M., Marinova, M., Fradette, L., Paris, J. (2012). Lignin recovery by acid precipitation in a kraft mill: An energy perspective. J-FOR: The Journal of Science and Technology for Forest Products and Processes 2(4), 28-32.

Kannangara, M. (2015). "Development and integration of acid precipitation based lignin biorefineries in Kraft pulping mills", PhD Thesis, Polytechnique Montreal.

Keshthkar, J. (2013). "Steam and water combined analysis, integration and efficiency enhancement in Kraft pulping mills", PhD Thesis, Polytechnique Montreal.

Keshthkar, M., Ammara, R., Perrier, M., Paris, J. (In press). "Energy efficiency analysis and enhancement of three Canadian Kraft mills", J-FOR, (In press).

Kouisni, L., Holt-Hindle, P., Maki, K., \& Paleologou, M. (2012). The lignoforce system: A new process for the production of high-quality lignin from black liquor. J-FOR: The Journal of Science and Technology for Forest Products and Processes, 2(4), 610.

Mateos-Espejel, E., Savulescu, L., Maréchal, F., Paris, J. (2011). "Unified methodology for thermal energy efficiency improvement: Application to Kraft process", Chemical Engineering Science, 66(2), 135-151.

Meunier, F. (2008). "Domestiquer l'effet de serre: Energie et developpement durable" [Harnessing the greenhouse effect: Energy and Sustainable Development], Collection Universciences, Dunod ed., Paris.

Tomani, P. (2010). The lignoboost process. Cellulose Chemistry and Technology, 44(13), 53-58. 
